\title{
Editorial
}

\section{Programa de Pós-graduação em Cardiologia e Ciências Cardiovasculares da Faculdade de Medicina da Universidade Federal do Rio Grande do Sul}

\author{
Nadine Clausell, Flávio D. Fuchs, Waldomiro C. Manfroi, Jorge Pinto Ribeiro \\ Porto Alegre, RS
}

O programa de Pós-Graduação em Cardiologia da Universidade Federal do Rio Grande do Sul (UFGRS) iniciou suas atividades em 1976, sob a liderança do Prof. Eduardo Z. Faraco. Até hoje o Programa formou 80 Mestres e 41 Doutores, que hoje militam em instituições acadêmicas localizadas, principalmente, em Porto Alegre e interior do Rio Grande do Sul, mas, também, em outros estados brasileiros e em países latino-americanos. Atualmente, conta com 19 professores orientadores - 5 são pesquisadores CNPq, 22 alunos matriculados em nível de Mestrado e 19 em nível de Doutorado. No presente ano 7 doutores e 12 mestres concluirão seus cursos.

Histórico - Durante o final dos anos 70 e durante os anos 80, o curso era ministrado por professores da Faculdade de Medicina da UFRGS lotados no Hospital de Clínicas de Porto Alegre e no Instituto de Cardiologia. Como a pós graduação senso strictu estava apenas iniciando na área médica, poucos professores tinham titulação em nível de Livre Docência e a maioria dos professores era composta de especialistas. Além disso, a produção científica recente do corpo docente era limitada a publicações nacionais. A configuração inicial do Programa se assemelhou aos então existentes na Faculdade de Medicina da UFRGS e em muitas instituições, privilegiando um perfil de especialização avançada. Suas disciplinas reproduziam em muito o conteúdo da prática cardiológica e, poucas vezes, eram ministradas por pesquisadores. Exceção notável era a disciplina de Fisiologia Cardiovascular, que trouxe a Porto Alegre pesquisadores líderes nacionais e com inserção internacional, como os professores Eduardo Moacir Krieger e Antônio Paes de Carvalho. Muitos alunos eram professores da própria Escola e somente uma pequena proporção concluiu seus mestrados ou doutorados ou os que concluíram, o faziam consumindo tempos excessivamente longos. Em 1986, houve uma tentativa de unificação dos quatro Cursos de Pós-graduação, então existentes na Faculdade de Medicina. Essa iniciativa resultou na criação do Curso de Clínica Médica, porém, posteriormente retomou-se o Programa de Pós-Graduação em Cardiologia. Também nesta época, o Instituto de Cardiologia da Fundação Universitária de Cardiologia formou seu próprio Programa de Pós-graduação que exigiu um realinhamento do corpo docente.

Programa de Pós-graduação em Cardiologia e Ciências Cardiovasculares, Faculdade de Medicina da Universidade Federal do Rio Grande do Sul

Endereço para correspondência - Profa. Nadine Clausell - Serviço de Cardiologia, Hospital de Clínicas de Porto Alegre - Rua Ramiro Barcelos 2350, Cep 90035-003, Porto Alegre - RS
A partir de 1990, iniciou-se um esforço para uma mudança radical no perfil acadêmico do corpo docente, com substituição progressiva de professores sem titulação em nível de doutorado por professores com titulação e com produção científica qualificada. Utilizando o competente sistema de bolsas de treinamento no exterior oferecido pela CAPES e pelo CNPq, jovens com perfil para a vida acadêmica foram enviados para programas de doutorado, programas de doutorado Sandwich e programas de pós doutorado em algumas dos mais importantes centros acadêmicos da América do Norte e da Europa, incluindo: instituições americanas como Harvard, Boston, Johns Hopkins, Cleveland Clinic, Duke, Carolina do Norte, Emmory, Washington; centros canadenses como Toronto e Ottawa; e centros europeus como Munique, Londres e Pisa. O programa de treinamento do corpo docente foi planejado de forma a evitar a endogenia e, aproveitando diferentes oportunidades, capacitar médicos pesquisadores em quase todas as áreas da cardiologia.

Os jovens pesquisadores que retornavam de períodos de treinamento no exterior passavam a desenvolver suas atividades de pesquisa na UFRGS, apoiados pelo Programa de Pós-graduação em Cardiologia. Assim como outras universidades federais brasileiras, a UFRGS tem como importante limitação a estabilidade de seu corpo docente, que associado ao fato da grande maioria dos professores da Faculdade de Medicina aposentarem-se somente aos 70 anos, impede uma renovação adequada. Além disto, a limitada disponibilidade de novas vagas por parte do Governo Federal para admissão de novos professores contribui para este quadro. Em meados dos anos 90 realizou-se um movimento para exigir o título de doutor para todos os futuros concursos para professores na UFRGS, o que permitiu a alguns recém doutores a integração o corpo docente da Faculdade de Medicina. Uma segunda estratégia de renovação utilizou a condição de empresa pública de direito privado do Hospital de Clínicas de Porto Alegre para renovar o corpo de médicos contratados, exigindo também a titulação de doutor para estes profissionais, que passaram, por sua vez, também a integrar o corpo docente da Pós-graduação. No final dos anos 80, o Programa de Pós-graduação em Cardiologia contava com apenas três professores orientadores com titulação em nível de doutorado e identificação com o Serviço de Cardiologia do Hospital de Clínicas de Porto Alegre. O esforço de formação de recursos humanos resultou que hoje em dia este grupo inclua 21 doutores, sendo que 14 tiveram formação pós-graduada no exterior.

Aos poucos foi se delineando nova filosofia para o desenvolvimento da pesquisa, alicerçada no perfil pesquisador/orientador de seus professores, com conseqüente modificação no processo seletivo 
de alunos. O Programa procurou focar seus objetivos em 3 pontos fundamentais: constituição de massa crítica com alta qualificação no corpo docente (jovens pesquisadores com evidente talento e vocação para pesquisa), seleção de candidatos com interesse genuíno em pesquisa e estímulo a produção científica com relevância e competitividade. Com o conjunto destas ações houve progressiva inserção internacional do Programa. A aceitação de alunos graduados em outras ciências profissionalizantes em saúde constituiu-se em passo decisivo para qualificar o corpo discente.

Qualificação do binômio aluno-orientador - Tradicionalmente, no Brasil, os modelos de Pós-graduação possibilitam a egressos das Faculdades de Medicina (e mais recentemente no nosso Programa, de profissionais não médicos) a busca de diferenciação científica. Infelizmente, os processos seletivos, muitas vezes burocratizados e impessoais, pressionados por demandas crescentes (profissionais que "precisam" sua titulação para progressão funcional) permitem o ingresso de alunos que em pouco contribuirão para o crescimento acadêmico no futuro, não justificando o dispêndio em tempo e recursos financeiros para sua titulação. Configura-se uma realidade perversa: a titulação de mestres e doutores sem a necessária independência para ampliar a produção científica de qualidade

Em outros países, o formato senso strictu da pós graduação não contempla o meio médico. O Master in Sciences ou o PhD são títulos primariamente afetos às áreas básicas. No meio médico, o pesquisador é ao mesmo tempo a figura principal e o objetivo a ser atingido, independente de Programas com estruturas curriculares formais com disciplinas, créditos, provas de suficiência. 0 que vale é produção de qualidade e crescente. 0 profissional cresce no seu meio acadêmico na direta proporção de sua capacidade de gerar conhecimento, reconhecida através da publicação de suas pesquisas (indagações, modelos experimentais, etc) em periódicos com revisores externos e independentes. Este é o modelo que o Programa de Pós-graduação em Cardiologia e outros Programas da UFRGS de modo geral vem buscando nos últimos anos, guardadas as proporções de massa crítica e limitado pelo modelo ortodoxo ainda vigente no país.

Independentemente da configuração e exigências formais da Pós-graduação tradicional, a qualidade de recursos humanos primariamente orientados à produção de conhecimento é fundamental no processo de qualificação do Programa. Assim, a renovação de seu corpo docente, privilegiando a incorporação de docentes e orientadores com este perfil é indispensável e requer um planejamento inicial, buscando vocações reais já na graduação. Os Programas de Iniciação Científica têm se mostrado eficientes na identificação e indução precoce destas vocações. Em nosso programa, candidatos que na graduação realizaram forte iniciação científica, podem conduzir o trabalho de mestrado durante o período de residência em cardiologia, diminuindo em muito o tempo para a conclusão do mestrado. A seguir, após realização de seus Mestrados na UFRGS, muitos têm sido expostos aos Programas de Doutorado Sandwich, o que na prática significa conviver in loco com o treinamento de research fellows. Esta prática também determinou, paulatinamente, o não investimento em alunos com propostas de Doutorado q.s.p (quanto satis para) ou seja a obtenção do título com um fim em si mesmo, sem compromisso com a densidade do material produzido ou de um investimento subsequente em pesquisa. Como conseqüência desta política, praticamente todos orientadores do Programa de Pós-graduação em Cardiologia tiveram formação em instituições líderes internacionais, sob coorientação de líderes de pesquisa locais. Após a finalização do investimento formal na formação de recursos humanos de alto nível, é fundamental integrar estes jovens Doutores no Programa. Para tanto é necessário inovar, não temer a competição acadêmica e estimulá-los a continuar produzindo, incorporando seus talentos e em seus primeiros momentos, integrá-los em grupos de pesquisa para busca conjunta de recursos financeiros que fomentem suas pesquisas futuras.

Em paralelo com a qualificação de seus docentes, o nosso Programa mudou, acentuadamente, o processo seletivo de alunos. Atualmente é necessário que, previamente ao ingresso, já haja projeto de pesquisa bem delineado, muitas vezes já em andamento, sob liderança do orientador que aceita orientar o candidato. Há exame seletivo e de nivelamento entre todos os Programas da Faculdade de Medicina, com conteúdos de Bioética, Epidemiologia Clínica e Bioestatística. Poucos alunos ingressam como alunos regulares, pois a maioria cumpre período de aluno especial, onde tem a oportunidade de demonstrar seu real potencial para tornarse um pesquisador independente.

A conclusão de mestrado e doutorado também espelha o perfil atual do Programa. Ao invés de apresentar as tradicionais dissertações e teses, freqüentemente destinadas a mofar em prateleiras de bibliotecas, é necessário apresentar pelo menos um artigo pronto para envio a revista internacional. Alunos de doutorado só são aceitos se já publicaram anteriormente seu trabalho de mestrado ou demonstraram sólida competência para pesquisa em outro contexto.

A qualificação do binômio orientador-aluno se dá em diversas linhas de pesquisa do Programa. Estas linhas de pesquisa valemse de modelos experimentais, clínicos e epidemiológicos. As pesquisas com modelos clínicos e epidemiológicos se deram em maior número na história do Programa, mas atualmente há um desenvolvimento crescente de linhas de pesquisa experimentais progressivamente integradas aos objetivos do Programa. Independentemente do objeto específico da questão de pesquisa, há vínculo entre todas pela lógica da pesquisa cardiovascular e pela qualidade indispensável para sua realização.

Estrutura e recursos financeiros para o desenvolvimento da pesquisa - A continuada qualificação dos Programas de Pós-graduação está intimamente ligada à disponibilidade de recursos financeiros para pesquisa. No entanto, o fomento à Pós-Graduação por parte das agências de financiadoras se dá principalmente através de bolsas, sendo insuficiente o fomento para pesquisa propriamente dita. Neste aspecto ocorre um descompasso entre o modelo de financiamento da Pós graduação brasileira e a exigência de crescimento acadêmico científico. De fato, a busca de recursos para o desenvolvimento de pesquisa por parte dos pesquisadores (orientadores) se dá junto às agências oficiais, como CNPq, Fundações estaduais, através de diversos editais, sem atrelamento direto com Programas de Pós. Ou seja, não há no orçamento da Pósgraduação verbas sistemáticas de fomento expressivas, com alocação proporcional para serem disputadas pelos Programas de Pós graduação, baseada por exemplo, na produção científica do seu corpo docente. Entretanto, em anos recentes houve fomento suplementar da CAPES com vistas à associação de grupos de pesquisa, com o que se possibilitou a estruturação, pelo menos parcial, de um Laboratório de Pesquisa Cardiovascular do Programa 
dirigido à investigação básica, localizado no Centro de Pesquisas do Hospital de Clínicas de Porto Alegre. Esta estrutura tem possibilitado a pesquisadores que disponham de recursos para custeio de suas pesquisas, a execução de projetos que demandem experimentos na área básica. No entanto, para que esta dinâmica se mantenha viável, a preocupação com financiamento é contínua. Neste sentido é importante manter um grupo de professores/ orientadores que seja competitivo do ponto de vista científico, capacitado a disputar verbas em diferentes níveis, nas diversas linhas de financiamento ou editais periodicamente existentes de agências oficiais. Além disto, para compensar parcialmente a falta de continuidade do fluxo de verbas de pesquisa, professores da pós-graduação colaboram em ensaios clínicos patrocinados pela indústria farmacêutica e, ao invés de recolherem honorários, utilizam os recursos para financiar parte das pesquisas geradas no próprio Programa. Finalmente, a busca de financiamentos de agências internacionais deve ser melhor explorada

Produto final - produção científica de qualidade - A política de agregação crescente de massa crítica qualificada ao corpo de professores orientadores, em detrimento de indivíduos menos produtivos, e a disponibilidade, embora ainda limitada, de recursos financeiros custeando os projetos de cada pesquisador têm permitido a progressiva melhora naquele que consideramos o melhor índice de avaliação de desempenho de Programas de Pós-graduação: a produção científica qualificada, com inserção internacional. Nos últimos 3 anos, a média anual publicações completas em revistas internacionais foi de 20 artigos realizados pelo núcleo produtivo de pesquisadores e seus orientandos.

A avaliação da Pós-graduação - Os objetivos e métodos empregados no Programa de Pós-graduação em Cardiologia e nos demais de nossa escola demonstram claramente que o critério maior de sua excelência é sua capacidade de produzir ciência de qualidade com inserção de alunos de pós-graduação e, inclusive, de graduação. Por conseqüência, o processo de avaliação deve refletir esta realidade. Os avaliadores deste índice estão disponíveis internacionalmente, prestam serviços a baixo ou nenhum custo e são em geral altamente qualificados: são editores e revisores de revistas internacionais. Programas de Pós-graduação com professores e alunos que publicam internacionalmente passam pelo crivo destes avaliadores e certamente têm qualidade. A avaliação CAPES da Pós-graduação brasileira é uma experiência vitoriosa, pois moldou boa parte da qualidade da própria Pós-graduação. Peca ainda por se basear, em muito, em critérios paralelos e de menor importância, como o perfil de disciplinas, tempos de conclusão, a filiação dos professores e outros. Os professores que constituem os Comitês de avaliação da agência têm sinalizado para a necessidade de mudança do sistema, que vem ocorrendo progressivamente. Neste ínterim já tem conferido importância primordial à produção científica, em consonância com o exposto neste ensaio. O esforço do Programa de Pós-graduação em Cardiologia e Ciências Cardiovasculares da Faculdade de Medicina da UFRGS nas últimas décadas tem sido reconhecido pela CAPES, que qualificou o programa com grau 5 em sua mais recente avaliação.

Perspectivas - A experiência vivida no Programa de Pós-graduação em Cardiologia da UFRGS é certamente vitoriosa. Destaquese que desde seu início prevaleceu no Programa o mote de inovação e criação. Ao invés do lugar comum de queixas institucionais, procurou-se mudar a realidade vigente, entendendo-se que a pesquisa científica de qualidade, em grande parte, origina o progresso das nações e não é dela decorrente. Assim, cabe aos atuais responsáveis pelo Programa em Cardiologia da UFRGS manter sua inserção na qualificação da pesquisa em saúde no Brasil, em particular na Cardiologia. É hora de, em conjunto com outras instituições de excelência, promover o necessário desenvolvimento tecnológico agregado à produção científica. Por desenvolvimento tecnológico entenda-se não somente a produção de tecnologias industriais, mas também a tão necessária avaliação quantitativa dos agravos de saúde em Cardiologia e a promoção de meios eficazes para seu diagnóstico e controle. A experiência do Programa de Pós-graduação de Cardiologia e Ciências Cardiovasculares da Faculdade de Medicina da UFRGS indica que a estrutura de pós-graduação senso strictu é aplicável à área médica, desde que desenvolvida por cientistas criativos e produtivos, que estimulem o crescimento de colegas mais jovens e não se utilizem do recurso da estabilidade do emprego público para manter o status quo. 